\title{
Monitoring of a Large Wall Failure at Tom Price Iron Ore Mine
}

\author{
A.P. Day Rio Tinto Iron Ore, Australia \\ J.M. Seery Rio Tinto Iron Ore, Australia
}

\begin{abstract}
Towards the end of 2006, routine Electronic Distance Measurement (EDM) prism monitoring highlighted rapid acceleration of one prism. At this stage, there were no visible signs of failure close to the prism and all other monitoring points in the vicinity could no longer be read. The prism itself was situated on a berm that was no longer accessible. A week later the prism was still accelerating with the only evidence of wall movements being two sets of cracks, one $30 \mathrm{~m}$ below the prism near the pit floor and the other about $50 \mathrm{~m}$ above the prism, suggesting the possibility of a large scale wall failure. A GroundProbe Slope Stability Radar was available for a few days and was deployed to scan a large section of wall. After a day of radar monitoring it was apparent that movement was occurring over an area approximately $265 \mathrm{~m}$ wide and nearly $100 \mathrm{~m}$ high. Movement rates were up to $30 \mathrm{~mm}$ per day and accelerating rapidly. The eastern half of the pit below the affected area was closed off and failure commenced two days later. The radar remained at the site for the initial part of the failure allowing correlation of movement rates and magnitudes with those recorded by prism monitoring.
\end{abstract}

It appears that the failure mechanism is a combination of sliding on a fault plane, sliding on the contact between the Footwall Zone and the Mount McRae Shale and rock mass failure through the Dales Gorge Member to produce significant floor heave at the base of the failure.

\section{Introduction}

Rio Tinto's Tom Price Mine is located in the Pilbara region of Western Australia and produces iron ore from a number of open pits. The largest source of high grade iron ore is the South East Prongs (SEP) pit which is about $1200 \mathrm{~m}$ long, $700 \mathrm{~m}$ wide and $250 \mathrm{~m}$ deep. Mining is focused on the Dales Gorge sequence which has been deformed into an east west trending syncline.

Accelerated wall movements on the south wall at the end of 2006 resulted in the closure of the main haul ramp - then the only access into the pit. Failure of the pit slope commenced two days later and has continued for the six months up to the compilation of this paper. The slope movements were first detected using Electronic Distance Measurement (EDM) prism monitoring. A GroundProbe Slope Stability Radar (SSR) was subsequently deployed and monitored the wall before, during and after the onset of failure. Results from the two monitoring systems are compared.

Mapping around the failure and subsequent back analysis has proved the importance of major structural features in controlling slope stability.

\section{EDM prism monitoring}

The first indication of an impending failure in the south wall of the SEP pit was from (EDM) prism monitoring. Although several prisms had been installed along the south wall, dirt accumulation and rockfall damage had resulted in all but one prism being unreadable. The approximate location of the one remaining prism, STR147, is shown in Figure 5. This prism had shown low creep rates of around $0.09 \mathrm{~mm} /$ day from mid 2005 until the end of 2006. In December 2006 movement rates increased to $1.7 \mathrm{~mm}$ /day (Figure 1). Visual inspections of the wall were carried out using binoculars as direct access to the prism site was no longer possible and no other monitoring data was available for this area. Initially, there was no visual evidence of cracking, slumping or crest failure. The possibility of survey error was considered, as some data from previous months had shown high variability. 
Adjusted distance difference for str 147

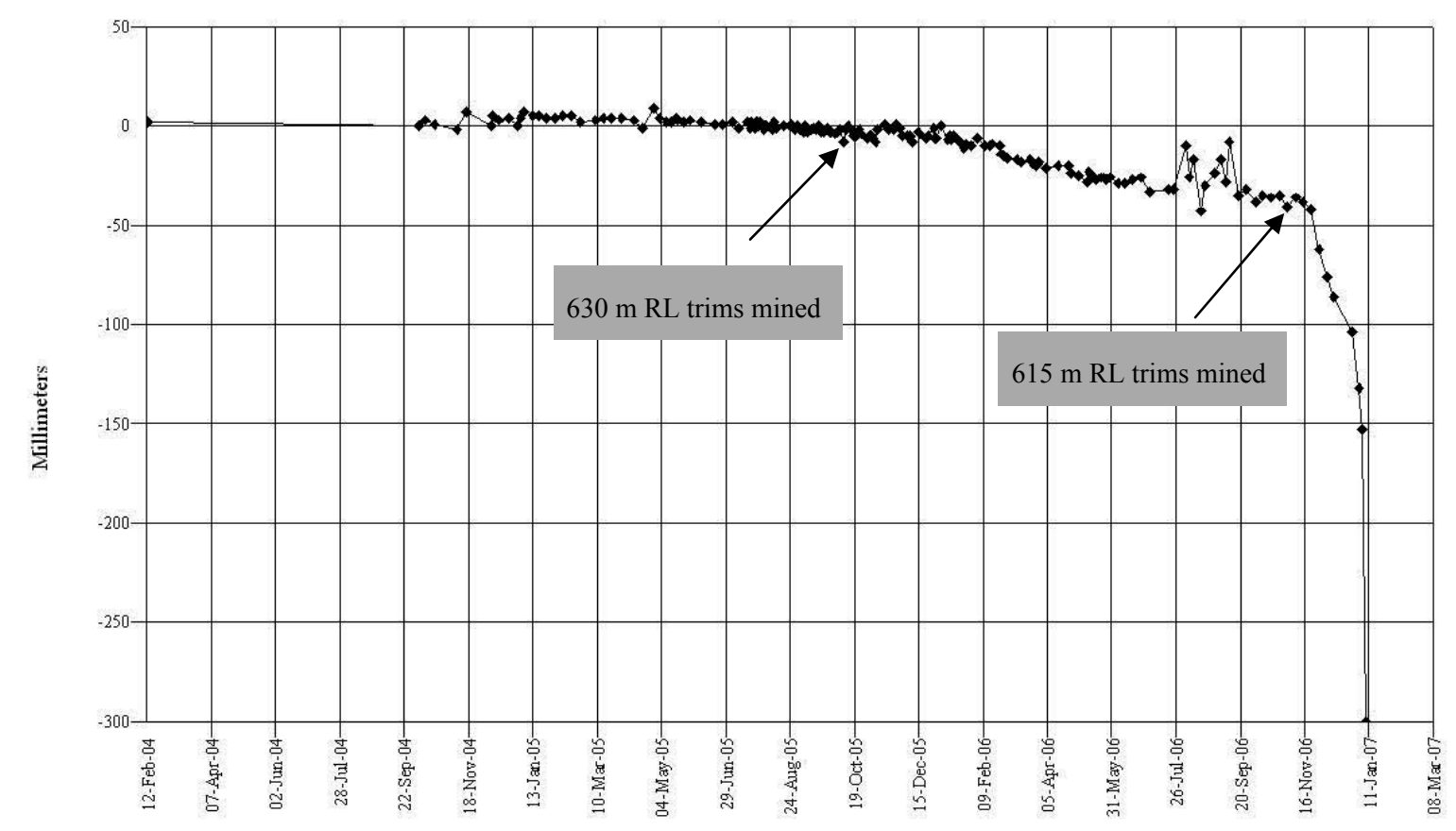

Figure 1 EDM prism monitoring data

Survey checks and further EDM readings over subsequent weeks confirmed that the prism continued to accelerate. In the first week of January 2007 movement rates increased to $5.5 \mathrm{~mm} /$ day. There was still no evidence of failure close to the prism but a horizontal tension cracks could be seen in a batter about $50 \mathrm{~m}$ above the prism. Some new berm failure was also evident about $35 \mathrm{~m}$ below the prism. At this point, the possibility of a large scale wall failure was considered, and the need for more data became apparent.

\section{Slope stability radar monitoring}

A Slope Stability Radar (SSR) was deployed to the SEP pit on 05 January 2007 in an attempt to confirm the movement indicated by the EDM prism monitoring and to help define the extent of the wall movement. Half a day of radar monitoring was enough to confirm that a large section of the wall was moving at rates of up to $200 \mathrm{~mm} /$ day (Figure 2). Two distinct "hotspots" were identified, one at the eastern end and one at the western end of the wall, with the central section having the lowest movement rate of around $60 \mathrm{~mm} / \mathrm{day}$. The pit was closed on 6 January 2007. 


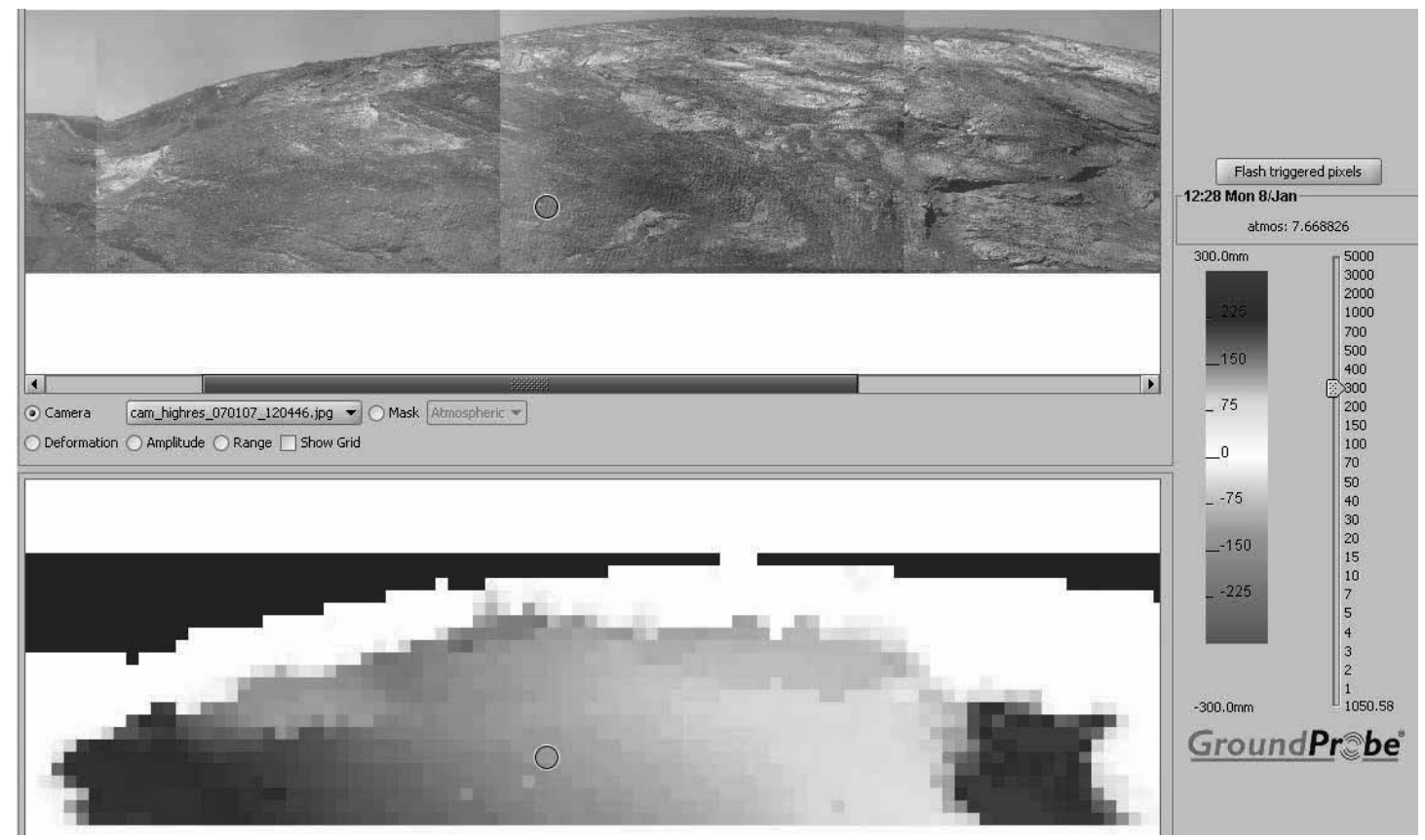

Figure 2 Radar scan showing pre-failure wall movements

Over the next two days wall movements accelerated rapidly until the commencement of failure on 8 January 2007. Figure 3 below shows displacement with respect to time averaged over the areas highlighted in green on the images. Failure initiated at the displacement "hotspot" at the western end of the wall (right hand side of the photograph). The distinct inflexion of the curve in the early hours of Monday morning correlates well with the estimated time of failure. Failure of the eastern end "hotspot" commenced a few days later.

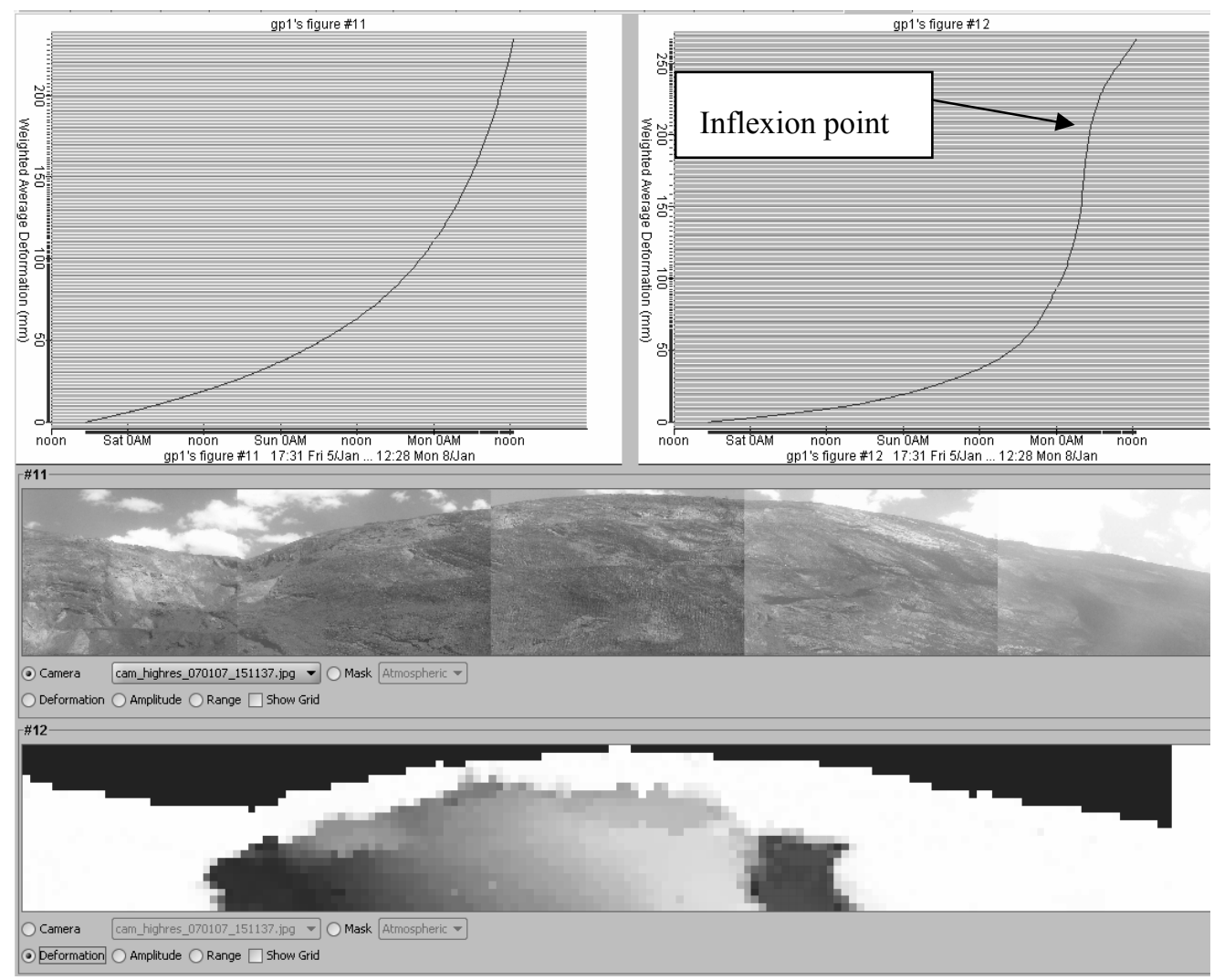

Figure 3 Acceleration in wall movement 
The extent of the failure area is $265 \mathrm{~m}$ across with a maximum vertical height of $135 \mathrm{~m}$. The thickness of failure is unknown but is thought to be less than $5 \mathrm{~m}$ at the top of the wall and greater than $20 \mathrm{~m}$ at the toe. Assuming an average thickness of around $8 \mathrm{~m}$ the total volume of failure is $350,000 \mathrm{~m}^{3}$. The failed material consists of a mixture of high grade ore, low grade ore and waste shales. The estimated mass of the failing material is around a million tonnes although it did not all collapse simultaneously.

\section{Comparison of SSR and prism data}

The location of EDM prism STR147 can be estimated in the SSR scans and direct comparisons made for certain periods of time when both systems were in place. After $300 \mathrm{~mm}$ of displacement down the wall, the prism could no longer be picked up from the original survey pillar. However, after a break of more than two months the survey team successfully triangulated the prism position from new locations and continued to track its movement for another $15 \mathrm{~m}$ of relative displacement down the wall, after which it was lost again.

Unfortunately the radar had to be moved several times over this period and therefore the total amount of displacement cannot be compared for this period. However, displacement rates at various times when both systems were in operation are compared in Figure 4 below. The large gap in the solid line represents the period when the prism was not monitored.

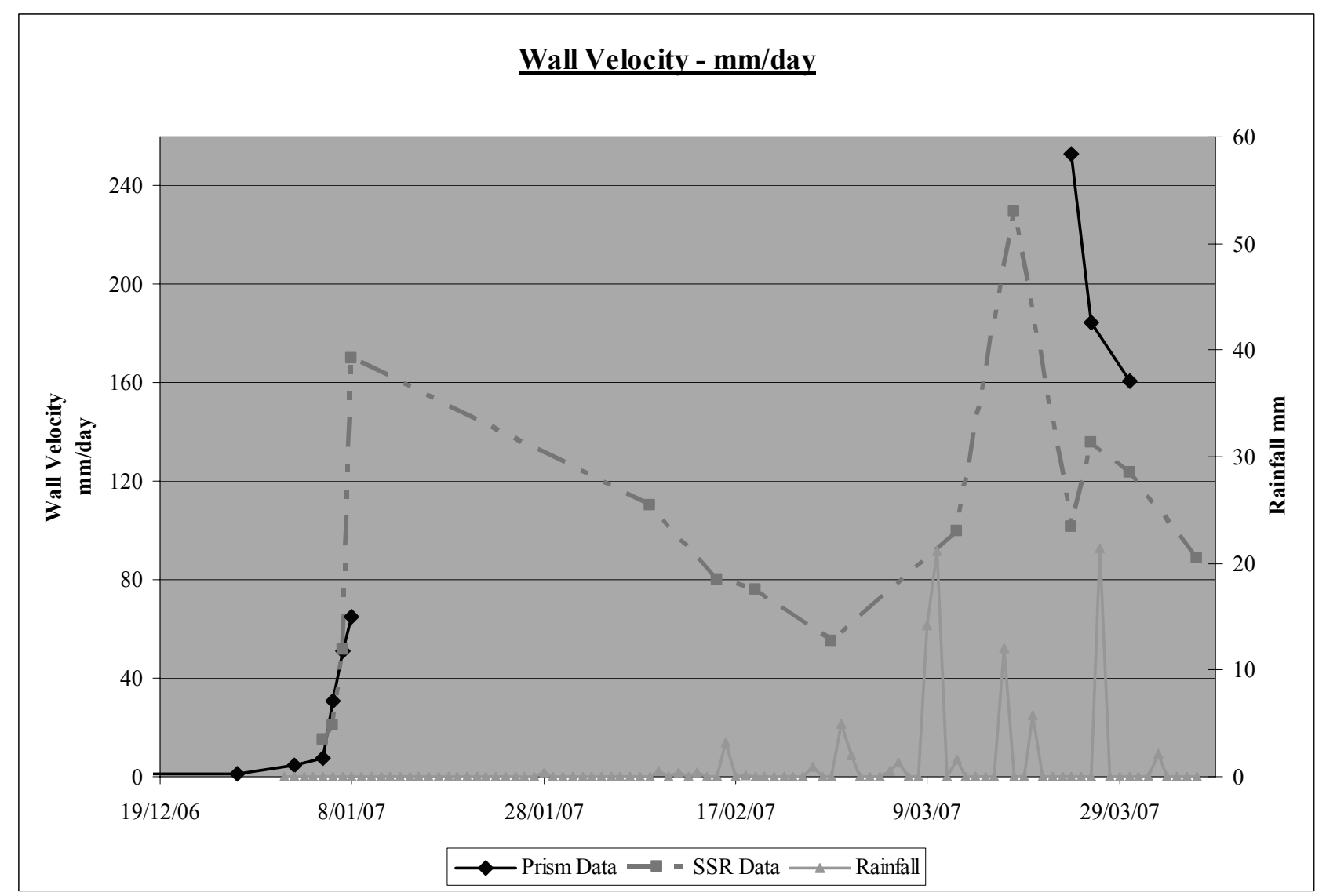

Figure 4 Comparison of EDM prism movement with SSR scan data

\section{Discussion of failure mechanism}

Various mechanisms appear to have contributed to this wall failure with geological discontinuities playing an important role. Within the broad synclinal structure of the SEP pit there is smaller scale parasitic folding on both limbs. Around the failure area, a plunging syncline within the southern limb of the main syncline (Figure 5) has resulted in a portion of Dales Gorge ore being left on the wall against the footwall waste rocks of the Mount McRae Shale unit. The contact between these two units is often weak and prone to failure and 
with the plunging syncline dipping out of the wall, a potential failure surface is created. The increased density of the ore remaining in the walls would also have contributed to the disturbing force of the failed material. Post failure mapping also identified a fault with a dip and strike very close to the bedding in this area. It seems likely that this feature also had an impact on the initiation of the failure.

Whether bedding or fault initiated failure, there is some evidence that it was not purely controlled by structural discontinuities. Two days after the initial failure commenced, the pit floor began to heave, as shown in Figure 5 below. This section of the pit floor had been graded flat right up to the pit wall two days prior to the onset of failure. The most likely explanation for the floor heave is a change from structurally controlled failure to a circular type rock mass failure. The pit floor continued to heave over the next few months as the failure progressed (Figure 6) and was some $10 \mathrm{~m}$ above the original elevation at the time of writing.

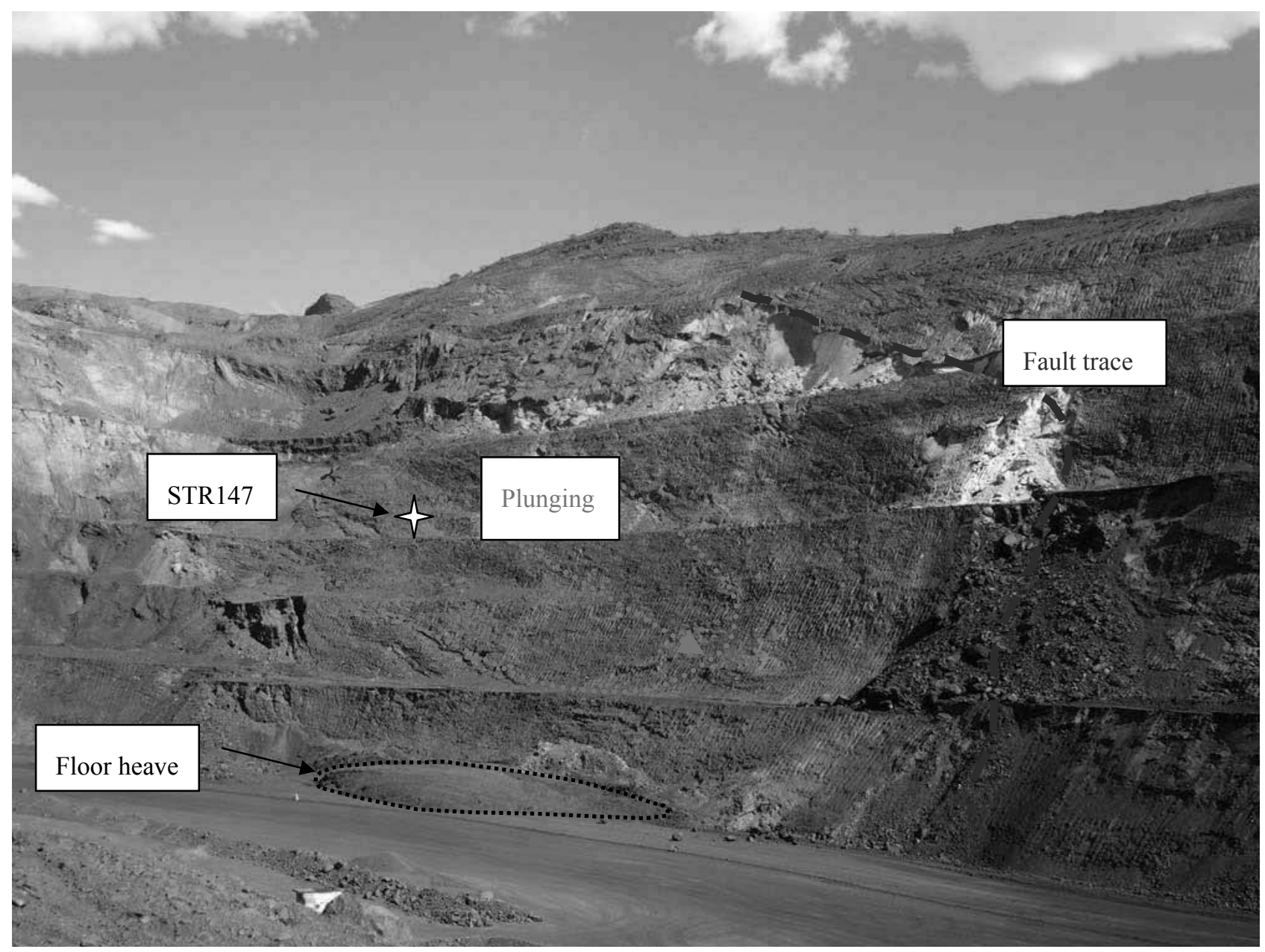

Figure 5 Onset of failure - 9 January 2007

\subsection{Failure triggers}

Analysis of the available data indicates that the main trigger for the wall failure in the SEP pit was the bench progression in the pit floor. The first indications of wall movement occurred at the end of 2005 when the $630 \mathrm{RL}$ mining took place. After this, prism data indicated steady creep at around $0.09 \mathrm{~mm} / \mathrm{day}$. With the mining of the 615 RL bench in November 2006 there was a dramatic increase in wall velocity up to the time of failure, after which the wall velocity decreased gradually from a peak of around $170 \mathrm{~mm} /$ day.

Rainfall data from various sources in or close to the pit does not correlate with the initiation of the failure but does correlate with a sudden increase in post failure deformation rates towards the end of March shown in Figure 4. These rainfall peaks are related to tropical cyclone George during which the wall velocity increased 
to over $200 \mathrm{~mm} /$ day. Since the end of the wet season the wall velocity has deceased steadily to around $20 \mathrm{~mm} /$ day in June 2007.

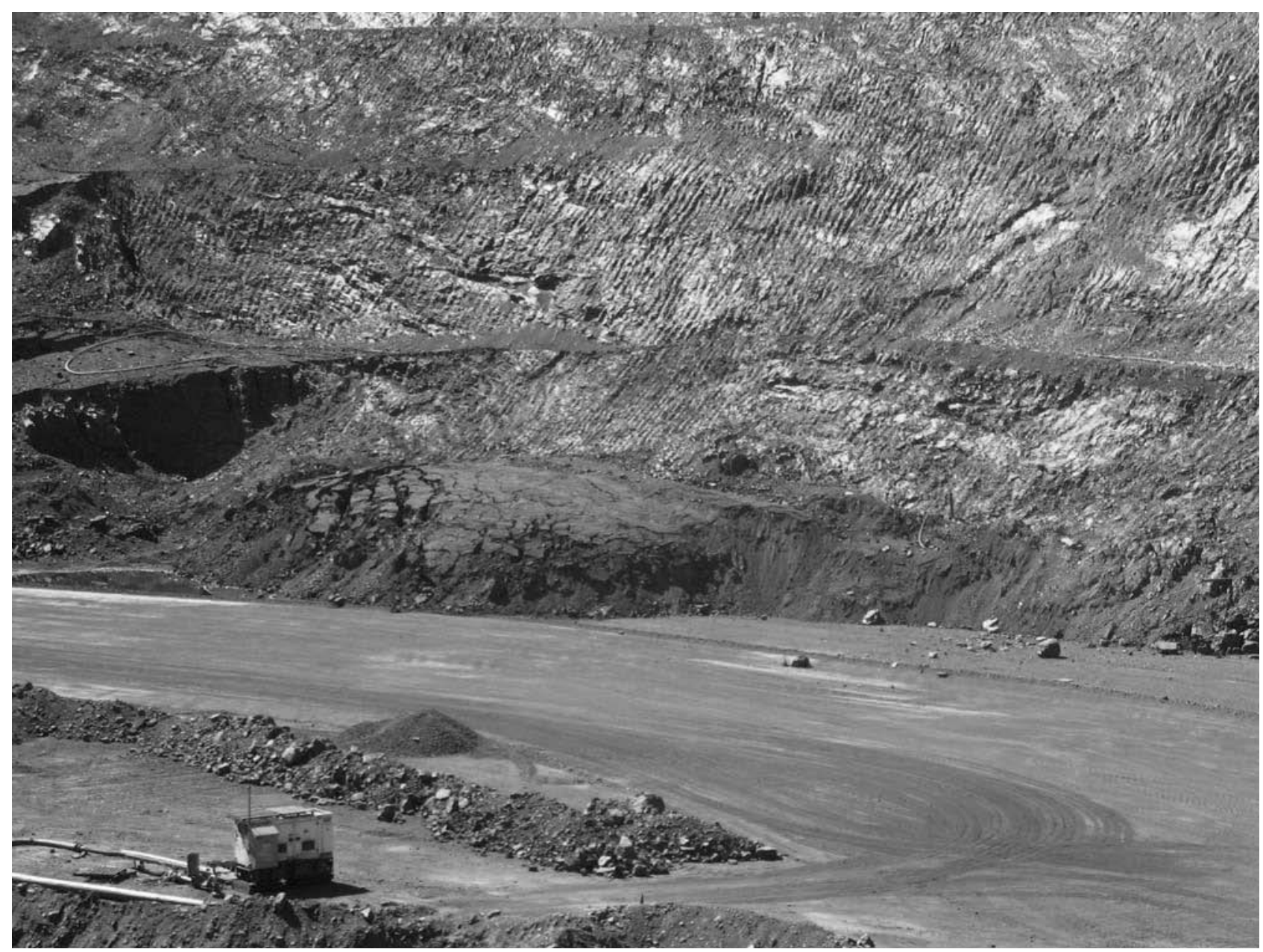

Figure 6 Floor heave - 6 February 2007

\subsection{Failure back analysis}

Using new structural geology data from post failure mapping, limit equilibrium analysis of the failure was undertaken with the Rocscience package, SLIDE ${ }^{\mathrm{TM}}$ (Rocscience, 2005). The water table was defined from piezometer readings. Using corrected Janbu type circular failure analysis, the factor of safety for a typical section through the area is 1.3 (Figure 7). This does not indicate failure by a purely circular mechanism.

It is postulated that the failure path started along the fault plane, followed the bedding contact at the base of the Mcrae Shale before breaking through the rock mass into the pit floor. This hypothesis was tested by using a defined failure path, which follows a cohesionless fault. The lowest resultant factor of safety, shown in Figure 8 , is 0.75 supporting the postulated failure path and highlighting the importance of major structural geological features in controlling slope failures. 


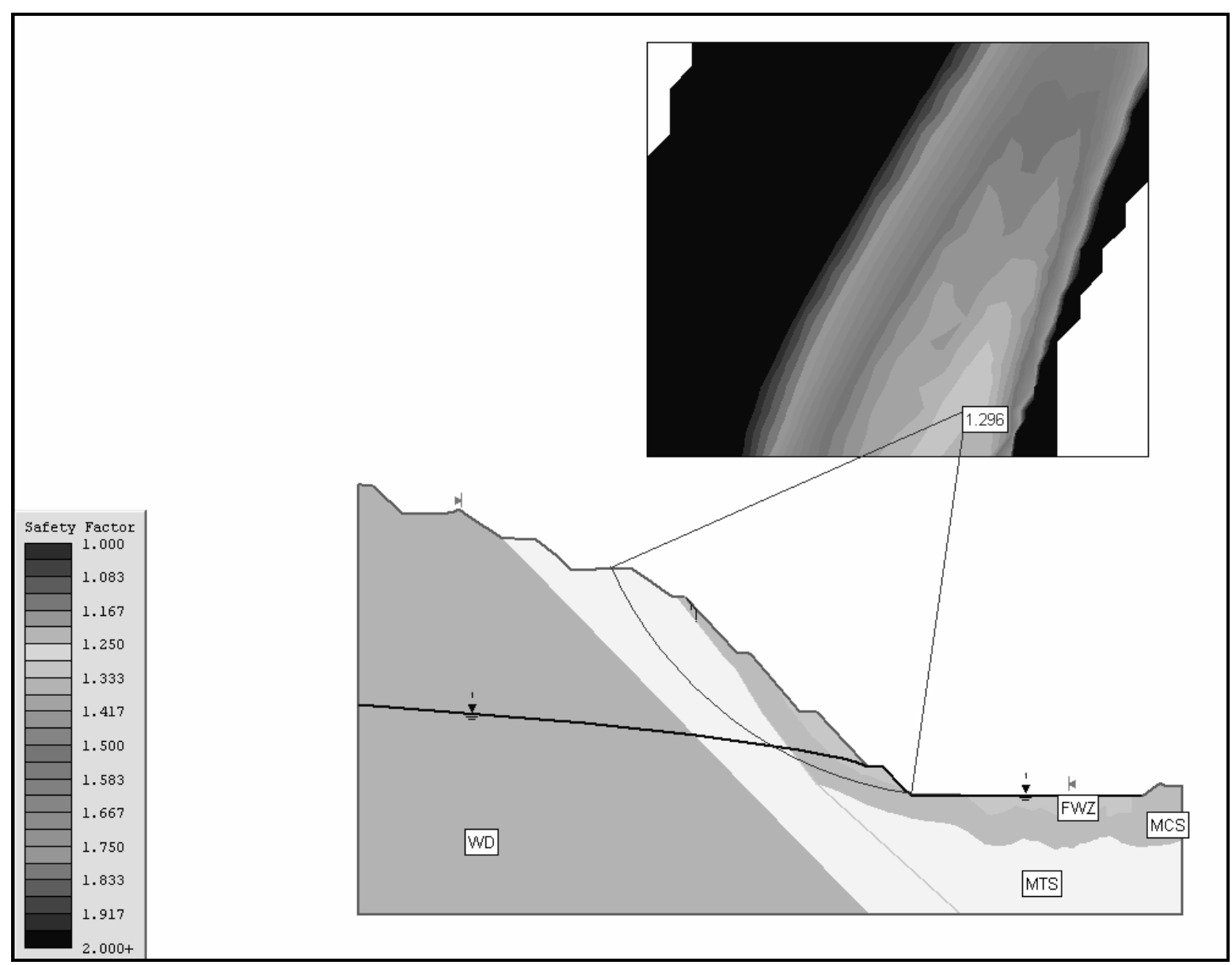

Figure 7 Slide model - circular failure

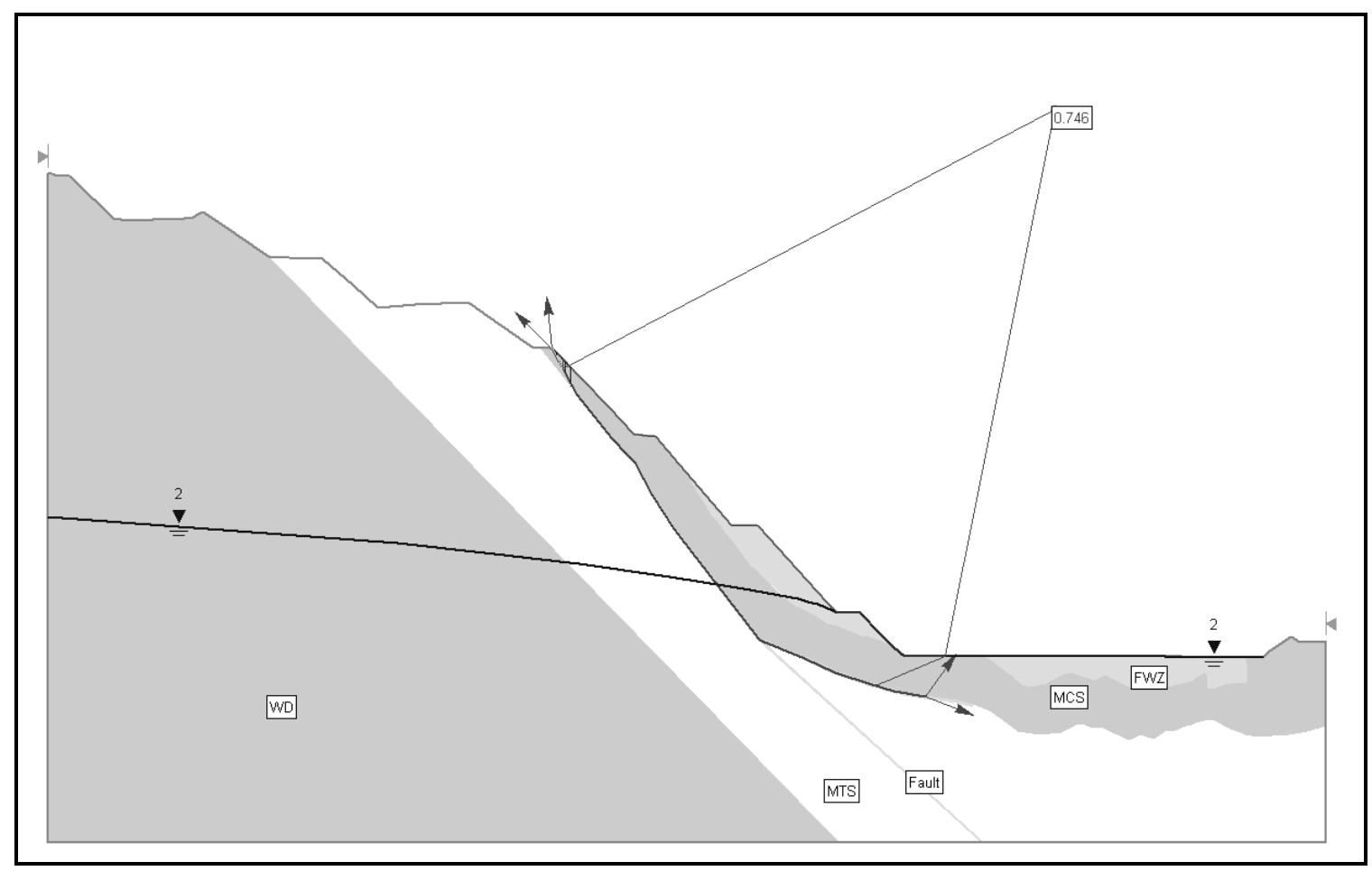

Figure 8 Slide model - defined path failure 


\section{Conclusions}

Despite high attrition rates for prisms in the area where the failure occurred, the prism monitoring system fulfilled its primary function of alerting the geotechnical team to accelerating wall movements in an area where there were no visible signs of impending failure. The SSR subsequently provided an accurate indication of the full extent of the failure on a section of wall with no other monitoring options. The pit was safely closed two days before slope failure commenced. Subsequent slope monitoring using EDM prisms and SSR scanning allowed a limited comparison of movement rates and magnitudes showing a fair correlation between the systems. With confidence gained in reliable monitoring systems and the virtually real-time nature of the SSR monitoring, the option of mining close to an active failure may be realised without compromising safety.

The slope monitoring programme at Tom Price Mine is expected to continue using both, radar and prism monitoring, as well as other systems. The prism monitoring is necessary for low cost, wide area coverage of the numerous, geographically dispersed pits. Where problem areas are identified, the SSR is invaluable for quantifying the extent of failure whilst giving reliable rates of movement. With this data, informed decisions can be made as to whether mining can continue safely.

Analysis of the monitoring data indicates that the SEP failure was induced by mining of the 615 RL bench and not directly by rainfall. However, the rate of deformation within the failure increased suddenly some three months after the onset of failure, probably in response to tropical cyclone George.

Back analysis of the failure mechanisms indicates that a large scale slope failure would not have been expected in this part of the pit without the presence of a major geological structure. The fault in question virtually parallels a lithological contact and was not identified prior to failure, thus highlighting the importance of detailed structural mapping.

\section{References}

Rocscience (2005) SLIDE Version 5.0, Rocscience Inc., Ontario, Canada, http://www.rocscience.com. 